\title{
High-resolution carbon dioxide concentration record $650,000-800,000$ years before present
}

\author{
Dieter Lüthi ${ }^{1}$, Martine Le Floch ${ }^{2}$, Bernhard Bereiter ${ }^{1}$, Thomas Blunier ${ }^{1} \dagger$, Jean-Marc Barnola ${ }^{2}$, Urs Siegenthaler ${ }^{1}$, \\ Dominique Raynaud ${ }^{2}$, Jean Jouzel ${ }^{3}$, Hubertus Fischer ${ }^{4}$, Kenji Kawamura ${ }^{1} \dagger \&$ Thomas F. Stocker $^{1}$
}

\begin{abstract}
Changes in past atmospheric carbon dioxide concentrations can be determined by measuring the composition of air trapped in ice cores from Antarctica. So far, the Antarctic Vostok and EPICA Dome $\mathrm{C}$ ice cores have provided a composite record of atmospheric carbon dioxide levels over the past 650,000 years ${ }^{1-4}$. Here we present results of the lowest $200 \mathrm{~m}$ of the Dome $\mathrm{C}$ ice core, extending the record of atmospheric carbon dioxide concentration by two complete glacial cycles to $800,000 \mathrm{yr}$ before present. From previously published data $^{1-8}$ and the present work, we find that atmospheric carbon dioxide is strongly correlated with Antarctic temperature throughout eight glacial cycles but with significantly lower concentrations between 650,000 and 750,000 yr before present. Carbon dioxide levels are below 180 parts per million by volume (p.p.m.v.) for a period of 3,000 yr during Marine Isotope Stage 16, possibly reflecting more pronounced oceanic carbon storage. We report the lowest carbon dioxide concentration measured in an ice core, which extends the pre-industrial range of carbon dioxide concentrations during the late Quaternary by about 10 p.p.m.v. to $172-300$ p.p.m.v.
\end{abstract}

Two deep ice cores have been drilled within the European Project for Ice Coring in Antarctica (EPICA). The drillings at both sites, one located in the Dronning Maud Land (DML) area at Kohnen Station $\left(75^{\circ} 00^{\prime} 06^{\prime \prime} \mathrm{S} ; 00^{\circ} 04^{\prime} 04^{\prime \prime} \mathrm{E}\right)$, the other at Concordia Station (Dome $\mathrm{C} ; 75^{\circ} 06^{\prime} 04^{\prime \prime} \mathrm{S} ; 123^{\circ} 20^{\prime} 52^{\prime \prime} \mathrm{E}$ ), have been stopped at or a few metres above bedrock at a depth of $2,774 \mathrm{~m}$ and $3,270 \mathrm{~m}$, respectively. EPICA produced climate records focusing, among others, on water isotopes, particulate and soluble aerosol species as well as greenhouse gases $^{4,8,9}$. For the latter, the analysis of the air entrapped in the ice is the only direct way to determine their concentrations for times before precise routine atmospheric measurements were done, that is, before 1958.

Carbon dioxide measurements on Dome $\mathrm{C}$ ice, focusing on the interval 390 to $650 \mathrm{kyr}$ before present, ВР $(2,700-3,060 \mathrm{~m})^{4}$, confirmed the strong coupling between $\mathrm{CO}_{2}$ and Antarctic temperature found ${ }^{1}$ in the Vostok ice core for the past $420 \mathrm{kyr}$. They also showed a range in $\mathrm{CO}_{2}$ about $30 \%$ smaller (180 to 260 p.p.m.v.) than for the Vostok interval (180 to 300 p.p.m.v.) related to cooler interglacials in the earlier period ${ }^{10}$.

Investigating the lowest $200 \mathrm{~m}$ of the Dome $\mathrm{C}$ core $(3,060$ $3,270 \mathrm{~m}$ ), we extend the existing $\mathrm{CO}_{2}$ records by two complete glacial cycles. The data set of the depth interval 3,060-3,190 m, to which two laboratories have contributed with three different air extraction techniques and two independent measurement methods, is shown in Fig. 1. The resolution of the samples extracted by a needle cracker and analysed by laser absorption spectroscopy (LAS) at the University of Bern averages $0.55 \mathrm{~m}$ resulting in a mean time resolution of $570 \mathrm{yr}$. The 47 values measured at LGGE in Grenoble (ball crusher and gas chromatography) covering depth levels around $3,062 \mathrm{~m}$, between 3,085 and $3095 \mathrm{~m}$, and below $3,120 \mathrm{~m}$, average slightly higher than neighbouring samples analysed at Bern (see Supplementary Information). Despite this difference, which seems to be larger for low concentrations, the Grenoble measurements confirm the shape of the Bern record. Further confidence in the accuracy of the record is given by LAS measurements of air extracted by sublimating the ice at selected depth levels (Fig. 1). Also, remeasurements of depths between 3,030 $\mathrm{m}$ and 3,060 $\mathrm{m}$ (615665 kyr BP) agree with earlier data ${ }^{4}$ within the experimental uncertainty (Fig. 2).

At a depth level of $3,178 \mathrm{~m}$, a $\mathrm{CO}_{2}$ value of 339 p.p.m.v. (average of four samples) with a large scattering between 264 and 477 p.p.m.v. is found (black arrow, Fig. 1). This artefact can be explained by the fact that this ice is from an ice-core section drilled towards the end of the season 2002-2003, when an ethanol-water mixture had to be added at the bottom of the borehole to allow further drilling. This caused partial melting at the outside of the core and subsequent refreezing when hoisting the core through colder sections of the bore hole. This is the only artefact discovered in the ice above $3,190.56 \mathrm{~m}$.

The part below $3,190 \mathrm{~m}$ is characterized by $\mathrm{CO}_{2}$ concentrations mainly fluctuating between 180 and 210 p.p.m.v. in both the LGGE and the Bern data. Because of disturbed ice stratigraphy ${ }^{8}$, this part of the core does not reflect a climatic signal. We therefore limit further discussion of our new data set to the shallower part above $3,190.56 \mathrm{~m}$, that is, back to the glacial corresponding to Marine Isotope Stage (MIS) 20, 800 kyr BP.

The main features of the record are as follows. Starting at a glacial level of 188 p.p.m.v. in MIS 20, the $\mathrm{CO}_{2}$ concentration rises by about 70 p.p.m.v. within $9 \mathrm{kyr}$. This slope is similar to the five glacialinterglacial transitions of the past $450 \mathrm{kyr}$ (see Supplementary Information for a detailed comparison). At the beginning of MIS $19, \mathrm{CO}_{2}$ attains its local maximum of 261 p.p.m.v., which is similar to the highest levels during MIS 13 and 15 but substantially lower than during the four recent interglacials. Similar to MIS 5 and $9, \mathrm{CO}_{2}$ drops by about 15 p.p.m.v. in MIS 19 to a slowly decreasing phase of about $10 \mathrm{kyr}$, before it declines in a sawtooth pattern to glacial levels. This slow decline in the $10 \mathrm{kyr}$ after the initial peak is in contrast to the slowly increasing $\mathrm{CO}_{2}$ levels in the Holocene and the even slower increase in MIS 11, despite the similar orbital configuration of these three periods.

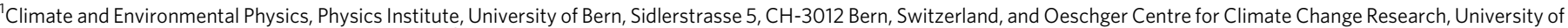
Bern, Erlachstrasse 9a, CH-3012 Bern, Switzerland. 'Laboratoire de Glaciologie et Géophysique de I'Environnement (LGGE), CNRS-Université Joseph Fourier Grenoble, 54 Rue

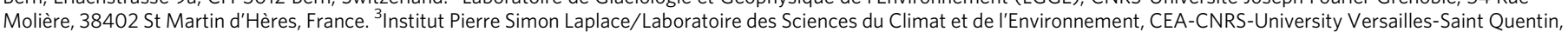

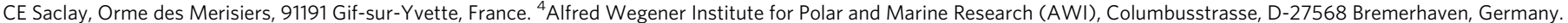

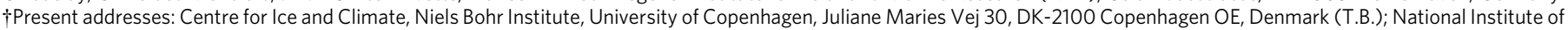
Polar Research, Research Organization of Information and Systems, 1-9-10 Kaga, Itabashi-ku, Tokyo 173-8515, Japan (K.K.). 


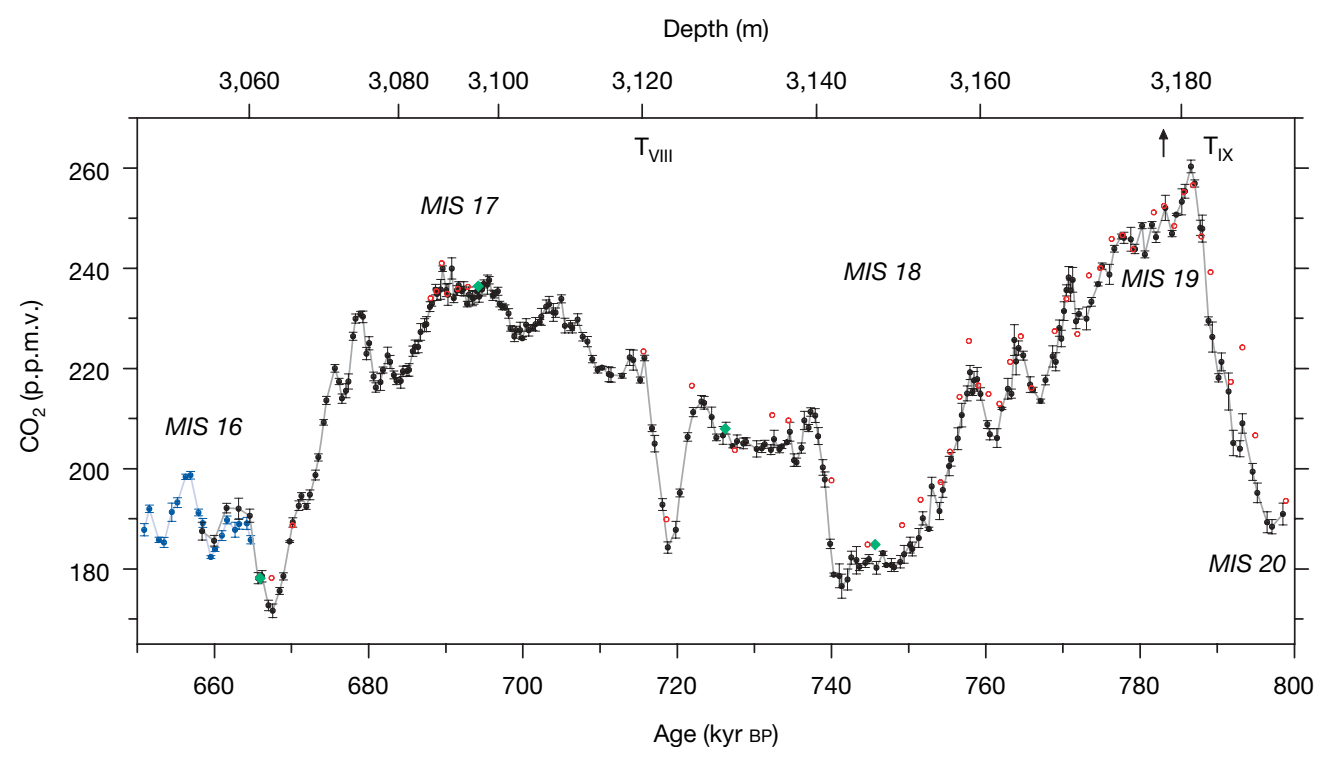

Figure 1 | Dome $\mathrm{C} \mathrm{CO}_{2}$ data. Black solid circles connected by a grey line: data measured at Bern (mean of four to six samples); error bars represent $1 \sigma$ of the mean (s.d.). Red open circles: data measured at Grenoble

$\left(2 \sigma=3\right.$ p.p.m.v.). Blue solid circles: Dome $\mathrm{C} \mathrm{CO}_{2}$ data published by

Siegenthaler et al. ${ }^{4}$. Green solid diamonds: control measurements with the

MIS 18 consists of two clearly separated phases. The earlier phase reaches its minimum of 177 p.p.m.v. just before a fast increase to the second, a phase of rather constant $\mathrm{CO}_{2}$ concentration between 205 and 212 p.p.m.v. lasting for $20 \mathrm{kyr}$. A rapid reduction by about 30 p.p.m.v. within a few thousand years, similar to MIS 15.2 and 15.4, and a similarly rapid increase by 40 p.p.m.v. (termination VIII) mark the beginning of the next interglacial. During the 40,000 yr of MIS 17, $\mathrm{CO}_{2}$ ranges between 215 and 240 p.p.m.v., which is significantly lower than in other interglacials during the past $800 \mathrm{kyr}$. At the beginning of MIS 16, $\mathrm{CO}_{2}$ remains below 180 p.p.m.v. for $3 \mathrm{kyr}$, most probably reflecting more pronounced glacial carbon storage in the ocean. During this period, $\mathrm{CO}_{2}$ falls to its lowest value ever found in ice cores, 172 p.p.m.v. (667 kyr BP), sublimation extraction technique. The black arrow indicates a $\mathrm{CO}_{2}$ value of $339 \pm 56$ p.p.m.v. (s.d.), an artefact detected at a depth of $3,178.12 \mathrm{~m}$ (age: $783,040 \mathrm{yr}$ BP). All data are plotted on the EDC3_gas_a age scale ${ }^{26}$. Glacial terminations are indicated using Roman numerals in subscript (for example $\mathrm{T}_{\mathrm{VIII}}$; MIS denotes Marine Isotope Stage ${ }^{27}$.

redefining the natural range of $\mathrm{CO}_{2}$ of the late Quaternary to about 170 to 300 p.p.m.v., before it rises at a rate of 8 p.p.m.v. $\mathrm{kyr}^{-1}$ to 190 p.p.m.v. at 665 kyr BP.

Figure 2 shows our data together with earlier results from the Dome C (650-390 kyr BP ${ }^{4}$ and 22-0 kyr BP ${ }^{5}$, Vostok ${ }^{1-3}$ (4400 kyr BP) and Taylor Dome ${ }^{6}(60-20 \mathrm{kyr} \mathrm{BP})$ ice cores resulting in a composite $\mathrm{CO}_{2}$ record over eight glacial cycles. During these $800 \mathrm{kyr}, \mathrm{CO}_{2}$ is strongly coupled with the Antarctic temperature $\left(r^{2}=0.82\right)$.

It was suggested earlier ${ }^{4}$ that there is a strong stationary relationship between Antarctic temperature and $\mathrm{CO}_{2}$. But our data reveal a significant deviation from this behaviour: The atmospheric concentration of $\mathrm{CO}_{2}$ during MIS 17 remains significantly below the levels

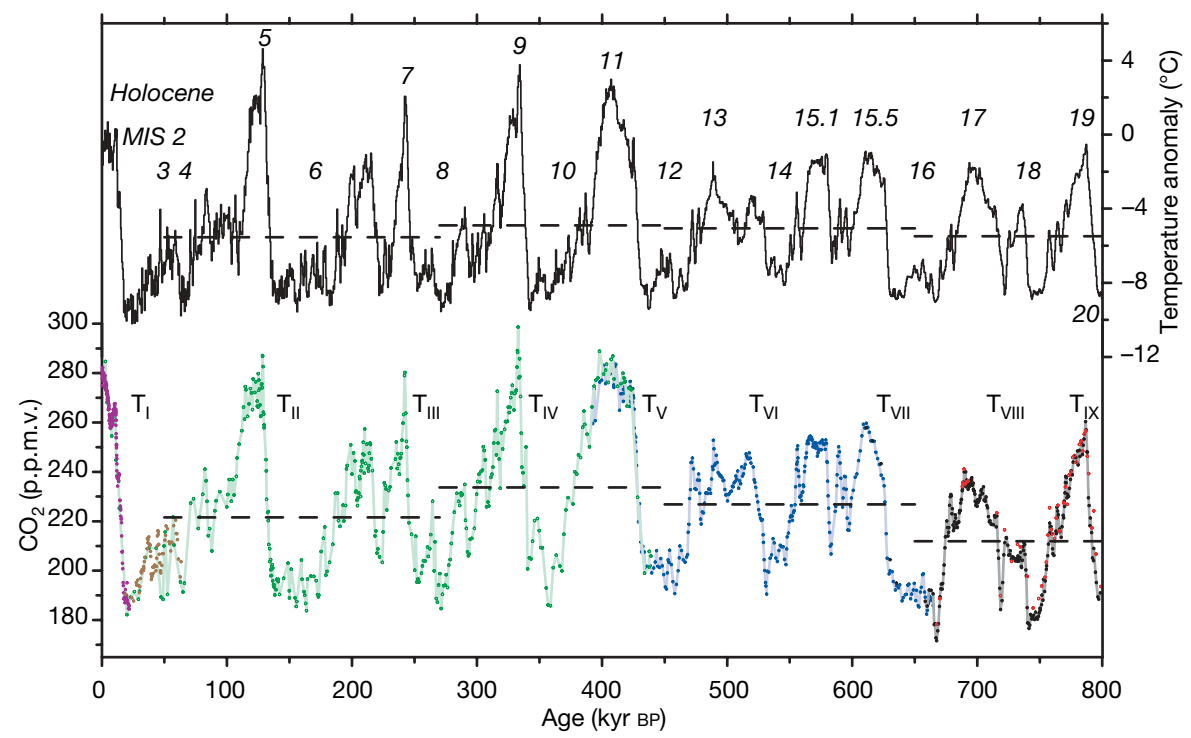

Figure 2 | Compilation of $\mathrm{CO}_{2}$ records and EPICA Dome $\mathrm{C}$ temperature anomaly over the past $800 \mathrm{kyr}$. The Dome $\mathrm{C}$ temperature anomaly record with respect to the mean temperature of the last millennium ${ }^{8}$ (based on original deuterium data interpolated to a 500 -yr resolution), plotted on the EDC3 timescale ${ }^{13}$, is given as a black step curve. Data for $\mathrm{CO}_{2}$ are from Dome $\mathrm{C}$ (solid circles in purple ${ }^{5}$, blue ${ }^{4}$, black: this work, measured at Bern; red open circles: this work, measured at Grenoble), Taylor Dome ${ }^{6}$ (brown) and Vostok $^{1-3}$ (green). All CO $\mathrm{CO}_{2}$ values are on the EDC3_gas_a age scale ${ }^{26}$. Horizontal lines are the mean values of temperature and $\mathrm{CO}_{2}$ for the time periods 799-650, 650-450, 450-270 and 270-50 kyr BP. Glacial terminations are indicated using Roman numerals in subscript (for example $\mathrm{T}_{\mathrm{I}}$ ); Marine Isotope Stages (MIS) are given in italic Arabic numerals ${ }^{27}$. 
during MIS 13, 15 and 19; this is expected neither from the temperature variations which always reach comparable levels during these interglacials nor from carbon cycle models ${ }^{11}$. Except for MIS 14, the temperature anomalies (relative to the mean temperature of the last millennium) of the coldest levels of all glacial periods range from around -9 to $-9.5^{\circ} \mathrm{C}$ with $\mathrm{CO}_{2}$ concentrations generally in the range 180-190 p.p.m.v.. Exceptions are MIS 16 and MIS 18 where we find significantly lower concentrations of $172-180$ p.p.m.v.. To illustrate this difference in the $\mathrm{CO}_{2}$ /temperature relationship before and after MIS 16, we calculate mean values for four different time intervals (799-650, 650-450, 450-270 and 270-50 kyr BP). All intervals start and end in the middle of a glacial including two interglacials (see Supplementary Information for details). Whereas averaged temperature anomalies of these four intervals $(-5.5,-5.1,-4.9$ and $-5.5^{\circ} \mathrm{C}$, respectively) only slightly differ from one another, the mean value of $\mathrm{CO}_{2}$ between 799 and $650 \mathrm{kyr}$ (212 p.p.m.v.) is 4-9\% lower than for the ensuing periods (227, 234 and 222 p.p.m.v.; see further illustrations in the Supplementary Information).

This shift is unexpected and takes place where the new measurement interval for this study begins. However, it seems to be a robust feature and not a measurement artefact, as we find no alteration in our $\mathrm{CO}_{2}$ record due to (1) enlarged amounts of impurities ${ }^{12}$, (2) increasing temperature with depth $\left(-7.2^{\circ} \mathrm{C}\right.$ at $3060 \mathrm{~m}$ to $-4.2^{\circ} \mathrm{C}$ at $3,200 \mathrm{~m}$, pressure melting point: $-2.3^{\circ} \mathrm{C}$ ) or (3) changes in the ice structure. Also, we observe no peculiarities in the preliminary $\mathrm{O}_{2} / \mathrm{N}_{2}$ and air content data (D. Raynaud and G. Dreyfus, personal communication) during this period. Furthermore, there is an overall good agreement between the data from Siegenthaler et al. ${ }^{4}$, the Grenoble and the Bern measurements (this work) using different extraction techniques. Taken together, we conclude that our record reflects the true atmospheric $\mathrm{CO}_{2}$ concentration.

Instead of $\mathrm{CO}_{2}$ concentrations being about 15 p.p.m.v. lower, the $\mathrm{CO}_{2}$ /temperature shift can also be explained by isotopic composition overestimating temperature by about $1{ }^{\circ} \mathrm{C}$. However, both the elevation $^{13}$ and moisture origin corrections on the estimated temperature change do not indicate a systematic overestimation of temperature between MIS 16 and 18 .

This implies that there could be a long-term $\mathrm{CO}_{2}$ increase by about 25 p.p.m.v. from 800 to $400 \mathrm{kyr}$ BP. Together with the long-term decrease of 15 p.p.m.v. during the past four glacial cycles, we suggest significant slow fluctuations in the atmospheric $\mathrm{CO}_{2}$ concentration on timescales of several $10^{5}$ years, probably influenced by changes in the weathering ${ }^{14}$ or by major reorganizations in the carbon reservoir of the global ocean ${ }^{15}$. Older ice is required to test hypotheses about any consistent long-term $\mathrm{CO}_{2}$ trend and a probable connection with the 500-kyr variations of the Quaternary carbon cycle found in marine records ${ }^{15}$.

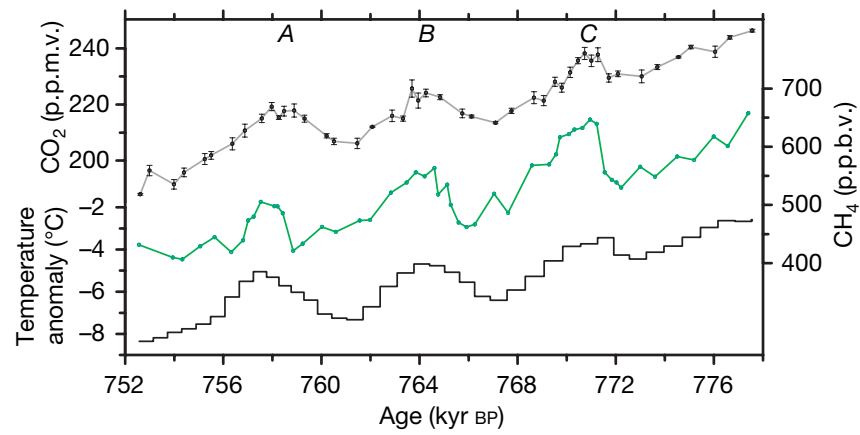

Figure 3 AIM events during MIS 18. Variations of Dome $\mathrm{C} \mathrm{CO}_{2}$ (black solid circles; mean of four to six samples; error bars are $1 \sigma$ of the mean (s.d.)), methane ${ }^{24}$ (green) and temperature anomaly based on the mean temperature of the past millennium ${ }^{8}$ (black step curve) between 778 and 752 kyr BP. Gases are plotted on the EDC3_gas_a age scale ${ }^{26}$, temperature on the EDC3 timescale ${ }^{13}$. The letters A to $\mathrm{C}$ denote the three events.
Besides long-term changes, the response of the carbon cycle to millennial climate change is of special interest. Indermühle et al. ${ }^{6}$ found four well-defined oscillations with a peak-to-peak amplitude of about 15 p.p.m.v. during the last glacial in the Taylor Dome ice core. These variations are concomitant to the larger of the Antarctic Isotope Maximum (AIM) events (Antarctic warming events with an amplitude of $\left.1-3{ }^{\circ} \mathrm{C}\right)^{7,16,17}$. AIM events are counterparts of the short and more pronounced warming events in the Northern Hemisphere known as Dansgaard-Oeschger events ${ }^{18}$, and hence are a manifestation of the bipolar seesaw ${ }^{19-21}$ with oceanic and terrestrial processes likely contributing to the reconstructed $\mathrm{CO}_{2}$ variations ${ }^{22,23}$.

The oldest trace of millennial-scale variations in our record is detected between 778 and $752 \mathrm{kyr}$ BP (Fig. 2). Antarctic temperature ${ }^{8}$, $\mathrm{CO}_{2}$ and the atmospheric concentration of methane ${ }^{24}$, whose variations are primarily affected by changes in Northern Hemisphere temperature and precipitation ${ }^{25}$, show three well-defined relative maxima (Fig. 3). A comparison of these data with the corresponding variations during MIS 3 reveals that all three quantities vary in the same range during both periods (see Supplementary Table 3). Furthermore, the rates of increase of $\mathrm{CH}_{4}$ for these three events in MIS 18 are similar to those in the EDC ice core during the large AIM events of MIS 3. Finally, the gradual rise of $\mathrm{CO}_{2}$ for events $\mathrm{A}$ and $\mathrm{B}$ precedes the rapid rise of $\mathrm{CH}_{4}$ by a few millennia, which is another typical feature of large AIM events in MIS $3^{7}$. Although the phasing for event $\mathrm{C}$ is less clear because of the relatively small $\mathrm{CO}_{2}$ increase, our findings provide strong support for an active bipolar seesaw during MIS 18.

\section{METHODS SUMMARY}

The analytical methods for routine $\mathrm{CO}_{2}$ measurements used at the University of Bern and at LGGE in Grenoble are based on dry extraction techniques followed by laser absorption spectroscopy and gas chromatography, respectively. In Bern, four to six samples $(23 \times 23 \times 16 \mathrm{~mm} ; 8 \mathrm{~g})$ from each depth level (every $550 \mathrm{~mm}$ ) in the ice core are measured in random order (two on the same day; the following two after all depth intervals have been measured twice). The samples are crushed by a cooled needle cracker under vacuum conditions. The sample container is connected to a cold trap for several minutes to release the air from the clathrates. Afterwards, the air is expanded to a measuring cell, where a laser is tuned six times over the absorption line of a vibration-rotation transition of the $\mathrm{CO}_{2}$

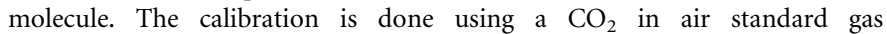
(251.65 p.p.m.v.) scaled on the World Meteorological Organization mole fraction scale.

In Grenoble, on every depth level one to three samples of about $40 \mathrm{~g}$ of ice are crushed under vacuum conditions. About 20 min later, the extracted gas is expanded in the sample loop of the gas chromatograph and analysed. Depending on the amount of the extracted air, three to five successive analyses are done. To avoid the possible influence of the water vapour injected with the gas, the $\mathrm{CO}_{2}$ ratio is calculated as the ratio between the $\mathrm{CO}_{2}$ peak and the air $\left(\mathrm{O}_{2}+\mathrm{N}_{2}\right)$ peak. The calibration is done using an Air Liquide standard scaled on three CSIRO standards (260.3 p.p.m.v., 321.1 p.p.m.v. and 172.8 p.p.m.v.).

\section{Received 12 October 2007; accepted 17 March 2008.}

1. Petit, J. R. et al. Climate and atmospheric history of the past 420,000 years from the Vostok ice core, Antarctica. Nature 399, 429-436 (1999).

2. Pepin, L., Raynaud, D., Barnola, J. M. \& Loutre, M. F. Hemispheric roles of climate forcings during glacial-interglacial transitions as deduced from the Vostok record and LLN-2D model experiments. J. Geophys. Res. 106, 31885-31892 (2001).

3. Raynaud, D. et al. The record for marine isotopic stage 11 . Nature $436,39-40$ (2005).

4. Siegenthaler, U. et al. Stable carbon cycle-climate relationship during the Late Pleistocene. Science 310, 1313-1317 (2005).

5. Monnin, E. et al. Atmospheric $\mathrm{CO}_{2}$ concentrations over the last glacial termination. Science 291, 112-114 (2001).

6. Indermühle, A., Monnin, E., Stauffer, B., Stocker, T. F. \& Wahlen, M. Atmospheric $\mathrm{CO}_{2}$ concentration from 60 to $20 \mathrm{kyr}$ BP from the Taylor Dome ice core, Antarctica. Geophys. Res. Lett. 27, 735-738 (2000)

7. Ahn, J. H. \& Brook, E. J. Atmospheric $\mathrm{CO}_{2}$ and climate from 65 to $30 \mathrm{ka} \mathrm{BP}$. Geophys. Res. Lett. 34, L10703, doi 10.1029/2007/GL029551 (2007).

8. Jouzel, J. et al. Orbital and millennial Antarctic climate variability over the last 800,000 years. Science 317, 793-796 (2007).

9. Wolff, E. W. et al. Southern Ocean sea ice extent, productivity and iron flux over the past eight glacial cycles. Nature 440, 491-496 (2006). 
10. EPICA Community Members. Eight glacial cycles from an Antarctic ice core. Nature 429, 623-628 (2004).

11. Köhler, P. \& Fischer, H. Simulating low frequency changes in atmospheric $\mathrm{CO}_{2}$ during the last 740000 years. Clim. Past 2, 57-78 (2006).

12. Lambert, F. et al. Dust-climate couplings over the past 800,000 years from the EPICA Dome C ice core. Nature 452, 616-619 (2008).

13. Parrenin, F. et al. The EDC3 chronology for the EPICA Dome C ice core. Clim. Past 3, 485-497 (2007)

14. Kump, L. R., Brantley, S. L. \& Arthur, M. A. Chemical weathering, atmospheric $\mathrm{CO}_{2}$, and climate. Annu. Rev. Earth Planet. Sci. 28, 611-667 (2000).

15. Wang, P., Tian, J., Cheng, X., Liu, C. \& Xu, J. Major Pleistocene stages in a carbon perspective: The South China Sea record and its global comparison. Paleoceanography 19, PA4005, doi:10.1029/2003PA000991 (2004).

16. Blunier, T. \& Brook, E. J. Timing of millennial-scale climate change in Antarctica and Greenland during the last glacial period. Science 291, 109-112 (2001).

17. EPICA Community Members. One-to-one coupling of glacial climate variability in Greenland and Antarctica. Nature 444, 195-198 (2006).

18. North Greenland Ice Core Project Members. High-resolution climate record of the Northern Hemisphere back into the last interglacial period. Nature 431, 147-151 (2004)

19. Broecker, W. S. Paleocean circulation during the last deglaciation: a bipolar seesaw? Paleoceanography 13, 119-121 (1998).

20. Stocker, T. F. The seesaw effect. Science 282, 61-62 (1998).

21. Stocker, T. F. \& Johnsen, S. J. A minimum thermodynamic model for the bipolar seesaw. Paleoceanography 18, 1087, doi:10.1029/2003PA000920 (2003).

22. Marchal, O. et al. Modelling the concentration of atmospheric $\mathrm{CO}_{2}$ during the Younger Dryas climate event. Clim. Dyn. 15, 341-354 (1999)

23. Köhler, P., Joos, F., Gerber, S. \& Knutti, R. Simulated changes in vegetation distribution, land carbon storage, and atmospheric $\mathrm{CO}_{2}$ in response to a collapse of the North Atlantic thermohaline circulation. Clim. Dyn. 25, 689-708 (2005)

24. Loulergue, L. et al. Orbital and millennial-scale features of atmospheric $\mathrm{CH}_{4}$ over the past 800,000 years. Nature doi:10.1038/nature06950 (this issue).

25. Siddall, M. et al. Using a maximum simplicity paleoclimate model to simulate millennial variability during the last four glacial periods. Quat. Sci. Rev. 25, 3185-3197 (2006).

26. Loulergue, L. et al. New constraints on the gas age-ice age difference along the EPICA ice cores, 0-50 kyr. Clim. Past 3, 527-540 (2007).

27. Lisiecki, L. E. \& Raymo, M. E. A. Pliocene-Pleistocene stack of 57 globally distributed benthic $\delta^{18} \mathrm{O}$ records. Paleoceanography 20, PA1003 (2005).

Supplementary Information is linked to the online version of the paper at www.nature.com/nature.

Acknowledgements This work is a contribution to the European Project for Ice Coring in Antarctica (EPICA), a joint European Science Foundation/European Commission scientific program, funded by the European Commission and by national contributions from Belgium, Denmark, France, Germany, Italy, the Netherlands, Norway, Sweden, Switzerland and the United Kingdom. The main logistic support was provided by IPEV and PNRA (at Dome C). We thank the technical team on the field and at both laboratories, G. Hausammann for helping with the $\mathrm{CO}_{2}$ measurements, and B. Stauffer, J. Schwander, M. Leuenberger, F. Joos, V. Masson-Delmotte, G. Dreyfus and C. Körner for their input. We acknowledge financial support by the Swiss NSF, the University of Bern, the Swiss Federal Agency of Energy and the French ANR (Agence nationale pour la Recherche; programme PICC). This is EPICA publication no. 194.

Author Information Reprints and permissions information is available at www.nature.com/reprints. Correspondence and requests for materials should be addressed to D.L. (luethi@climate.unibe.ch). 